\title{
Establishing a video Multidisciplinary Team meeting between Cameroon, Central Africa, and Leeds, UK, childhood cancer services
}

Bernard Wirndzem Njodzeka ${ }^{1}$, Glenn Afungchwi ${ }^{2}$, Francine Kouya ${ }^{2}$, Susan Picton ${ }^{3}$, Roly Squire $^{4}$, Brian Jator ${ }^{1}$, Vera Njamshi ${ }^{5}$, Richard Bardin ${ }^{1}$, Peter Hesseling ${ }^{6}$, Rachel Hollis ${ }^{7}$, Ghislain Feudjio ${ }^{1}$, and Jessica Morgan ${ }^{8}$

${ }^{1}$ Cameroon Baptist Convention Health Service

${ }^{2}$ Mbingo Baptist Hospital

${ }^{3}$ Leeds General Infirmary

${ }^{4}$ St. James University Hospital

${ }^{5}$ Cameroon Baptist Convention Health Board

${ }^{6}$ Stellenbosch University Faculty of Medicine and Health Sciences

${ }^{7}$ Leeds Children's Hospital

${ }^{8}$ University of York

October 4, 2021

\begin{abstract}
Abstract Background and aims Multidisciplinary team (MDT) meetings provide a regular, structured meeting of a core group of professionals to provide expert decision-making in individual patient care. We describe our experiences in establishing a virtual pediatric oncology MDT between twinning partners in Cameroon (4 hospitals) and the UK. Methods Monthly video conferencing MDT meetings were established in March 2019, initially using Google meet then using Zoom platforms. Case details were circulated using formal proformas. Standard operating procedures were outlined for the MDT conduct. Results There have been 269 discussions of 201 patients in 21 meetings. Patients have been varied in age (up to 24 years). Eighty-seven (43.3\%) patients had NHL, $16(8.0 \%)$ had Wilms tumour, 20 (10.0\%) had Acute Lymphoblastic Leukaemia, 19 (9.5\%) had Retinoblastoma and $59(29.4 \%)$ had other malignancies. Four of the patients did not have a malignancy. The majority of patients had stage $3(51,45.1 \%)$ or stage $4(59,52.2 \%)$. Nine patients had relapsed disease. Core team members reported positive benefits from the MDT, including defining goals of care, shared decision making, professional education and teambuilding. Conclusions Virtual MDT meetings between geographically dispersed teams are possible and have proved particularly valuable during the COVID-19 pandemic when in-person visits are not permitted. Cancer treatment cannot be done in isolation; the regular MDT meetings have paved the way for informed care through regular consultancy.
\end{abstract}

\section{Hosted file}

Cameroon MDT manuscript for PBC.docx available at https://authorea.com/users/439458/articles/ 540383-establishing-a-video-multidisciplinary-team-meeting-between-cameroon-centralafrica-and-leeds-uk-childhood-cancer-services

\section{Hosted file}

Cameroon MDT manuscript for PBC. Table 1.docx available at https://authorea.com/users/439458/ articles/540383-establishing-a-video-multidisciplinary-team-meeting-between-cameroon- 
central-africa-and-leeds-uk-childhood-cancer-services

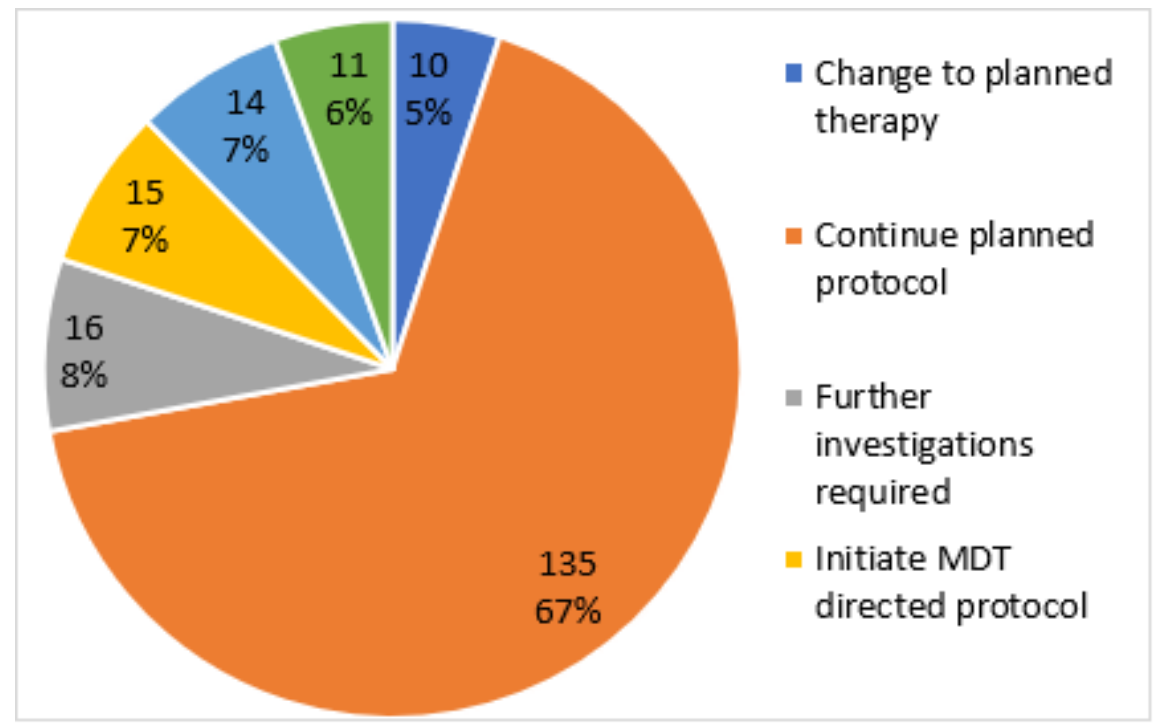

